\title{
Minor oral surgery on impacted lower third molar done by IIUM Undergraduates: a retrospective study
}

\author{
Azila Amirah Che Wahab' ${ }^{1}$, Nurul Izzani Zulkifle" Khairul Bariah Chi Adam², Nabilah Rashida \\ Jamali $^{*}$ \\ ${ }^{1}$ Kulliyyah of Dentistry, International Islamic University Malaysia, Kuantan, Pahang, Malaysia \\ 2Department of Oral Maxillofacial Surgery and Oral Diagnosis, Kulliyyah of Dentistry, International Islamic \\ University Malaysia, Kuantan, Pahang, Malaysia
}

\begin{abstract}
Minor oral surgery (MOS) is one of the important requirements for dental undergraduates to perform in Kulliyyah of Dentistry, IIUM. However, no assessment has been done on the suitability of the cases received by the students. Thus, this study was aimed to describe type of cases and level of difficulty in relation to undergraduate year of study. This study consisted of 97 subjects who had undergone MOS by IIUM undergraduate from September 2014 to October 2015. Data was collected from patient's documentation and orthopantomogram. Pederson index and relationship to inferior dental nerve were used to determine the difficulty index level. Statistical analysis was done using Chi-square test with statistical significance set at $\mathrm{p} \leq 0.05$. The mean age of the patients was 24 years old, with male to female ratio $1: 1.9 .52 .6 \%$ of the cases were indicated for surgery due to recurrent pericoronitis. The types of cases mostly received by undergraduates were Class IA (30.9\%) and Class IIA (48.5\%) with mesioangular impaction (39.2\%). Year 4 students received more difficult cases compared to Year $5(\mathrm{p}=0.504)$ with less complications postoperatively. Dental undergraduates received simple to moderate cases for MOS, and no significant association was found between year of undergraduate study and difficulty level of the cases.
\end{abstract}

Keywords: impacted tooth, minor oral surgery, difficulty level, wisdom tooth, third molar
Received:

23 July 2021

Revised:

11 February 2022

Accepted:

24 February 2022

Published Online:

4 March 2022

How to cite this article:

Che Wahab, A. A. ., Zulkifle, N. I.,

Chi Adam, K. B., \& Jamali, N. R.

Minor oral surgery on impacted

lower third molar done by IIUM

Undergraduates:

retrospective study. IIUM

Journal of Orofacial and Health

Sciences, 3(1), 84-94.

https://doi.org/10.31436/ijoh

s.v3i1.103

Article DOI:

10.31436/ijohs.v3i1.103

*Corresponding author

Address:

Kulliyyah of Dentistry, Jalan

Sultan Ahmad Shah, Bandar

Indera Mahkota, 25200

Kuantan, Pahang

Telephone: +6013 3686788

Email address:

nabilahrashida@iium.edu.my

\section{Introduction}

Lower third molar is the last tooth that erupts in the dentition, and it is the most frequently impacted tooth (Hupp, 2014). Minor oral surgery (MOS) on impacted lower third molar was reported as the most common surgical procedures done by the dentists (Ali et al., 2014; Susarla et al., 2003). This surgery involves several steps starting from the soft tissue flap elevation, bone guttering, and/or tooth sectioning (Batal \& Jacob, 2006). In Malaysia, it is accounted as one of the clinical requirements that needs to be fulfilled by the dental undergraduates during their clinical years in dental school.
MOS, however, may lead to various risks \& complications such as swelling, pain, paresthesia, alveolar osteitis, mandibular angle fracture, hemorrhage and trismus (Bataineh, 2001; Fuselier et al., 2002; Gülicher \& Gerlach, 2001; Halmos et al., 2004; Hill et al., 2001; Krimmel \& Reinert, 2000; Susarla et al., 2003).

The factors that determine the difficulties of the surgery are tooth angulations, root forms, number of roots, relative depth, space availability, relationship to inferior alveolar nerve, and relative horizontal position (Yuasa et al., 2002). Radiological assessment is valuable as it shows important details which determine the difficulty level of the 
surgery (Blaeser et al., 2003; Yuasa et al., 2002). The assessment of this is essential in order to allow proper planning and management of the patient (Susarla \& Dodson, 2004). Good surgical skills and technique, and application of the correct surgical principles are important in order to prevent further complications (Evans et al., 2002).

The difficulty level of the surgery may be determined by using Pederson Index. The index score is calculated based on the radiographic findings, which include depth of the tooth, ramus relationship, and angulation of the tooth (Bali et al., 2013; Yuasa et al., 2002). Depth of impacted third molar in relation to occlusal plane along with the distance or width between the vertical ascending mandibular ramus and the distal surface of the second molar were assessed by adapting Pell and Gregory's classification as described below (Figure $1 \& 2$ ).
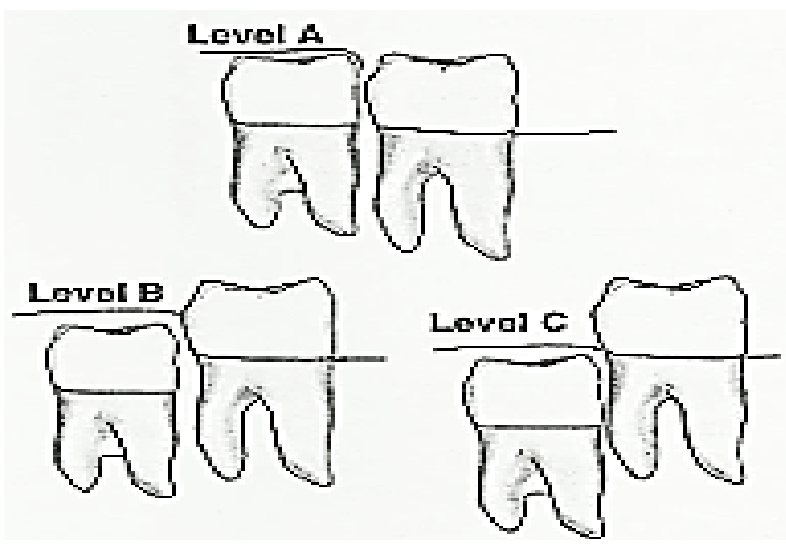

Figure 1. Classification based on the depth of third molar in relation to second molar

Class A: The occlusal level of the third molar is at the same level as the second molar.

Class B: The occlusal level of the third molar is between the occlusal of second molar and cementoenamel junction of the second molar.

Class C: The occlusal level of the third molar is below the cemento-enamel junction.
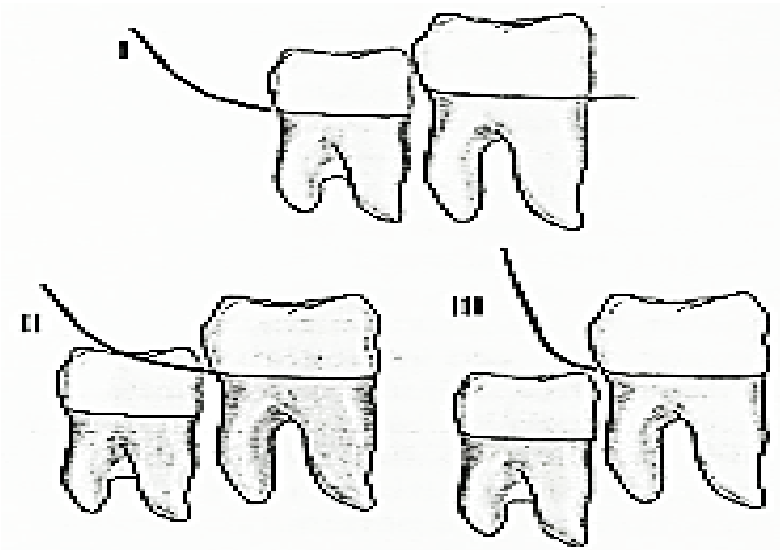

Figure 2. Classification based on ramus relationship

Class I: There is sufficient space between distal of the second molar to the ramus for the mesiodistal width of the crown of the third molar.

Class II: There is no sufficient space between distal of the second molar to the ramus, in which the crown of the third molar partially embedded in the ramus.

Class III: Most or the entire crown of the third molar embedded in the ramus. 
Type or angulation of the impacted third molar was adapted from Winter's classification with reference to the angle formed between the intersected longitudinal axes of the second molar and third molar. It is either, (a) mesioangular impaction, (b) distoangular impaction, (c) vertical impaction, or (d) horizontal impaction (Figure 3).

Then, the total scores of these three criteria are summed up and is classified into easy ( 3 to 4 ), moderate (5 to 6 ), and difficult ( 7 to 10). (Table 1).
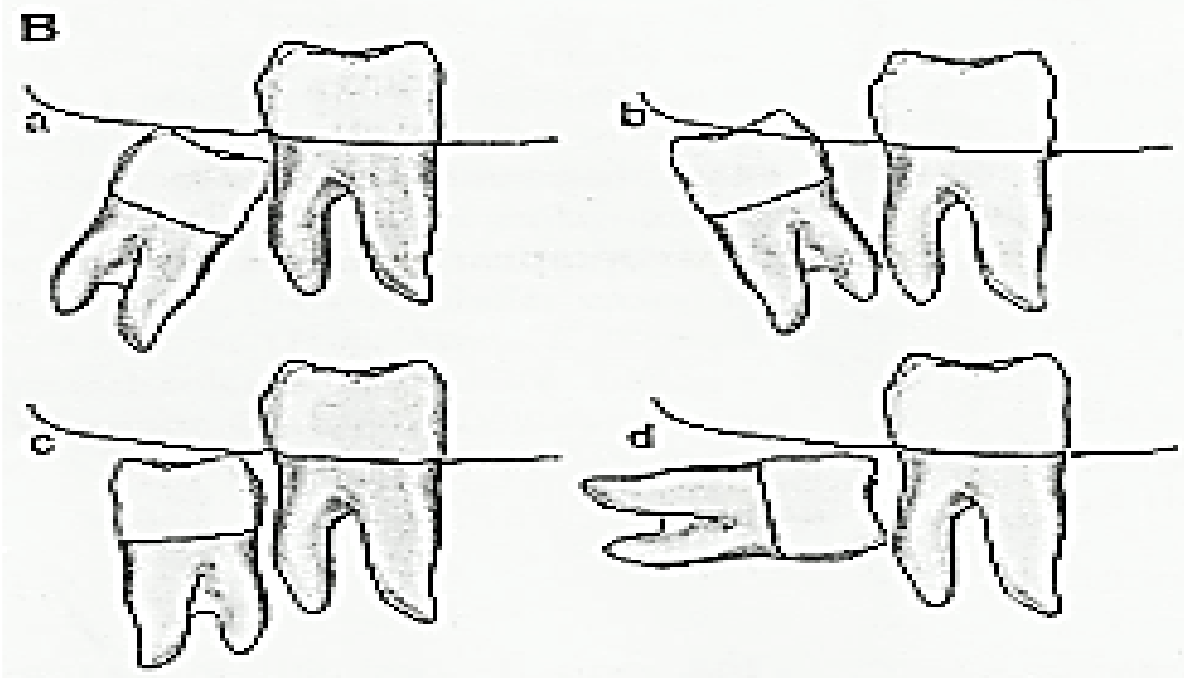

Figure 3. Angulation of the third molar

Table 1. Pederson Index from Textbook of Oral and Maxillofacial Surgery 3rd Edition, Neelima Anil Malik

\begin{tabular}{lcc}
\multicolumn{2}{c}{ Pederson Index: Difficulty index for removal of impacted lower third molars } \\
Classification & Difficulty index value & Difficulty index (Total) \\
Mesioangular & Angulation \\
Horizontal/ Transverse & 1 & \\
Vertical & 2 & \\
Distoangular & 3 & \\
& 4 & Easy: $3-4$ \\
Level A & Depth & Moderate: $5-6$ \\
Level B & 1 & Difficult: 7 - 10 \\
Level C & 2 & \\
& 3 & \\
Class I & 1 & \\
Class II & 2 & \\
Class III & 3 & \\
& Ramus relationship &
\end{tabular}



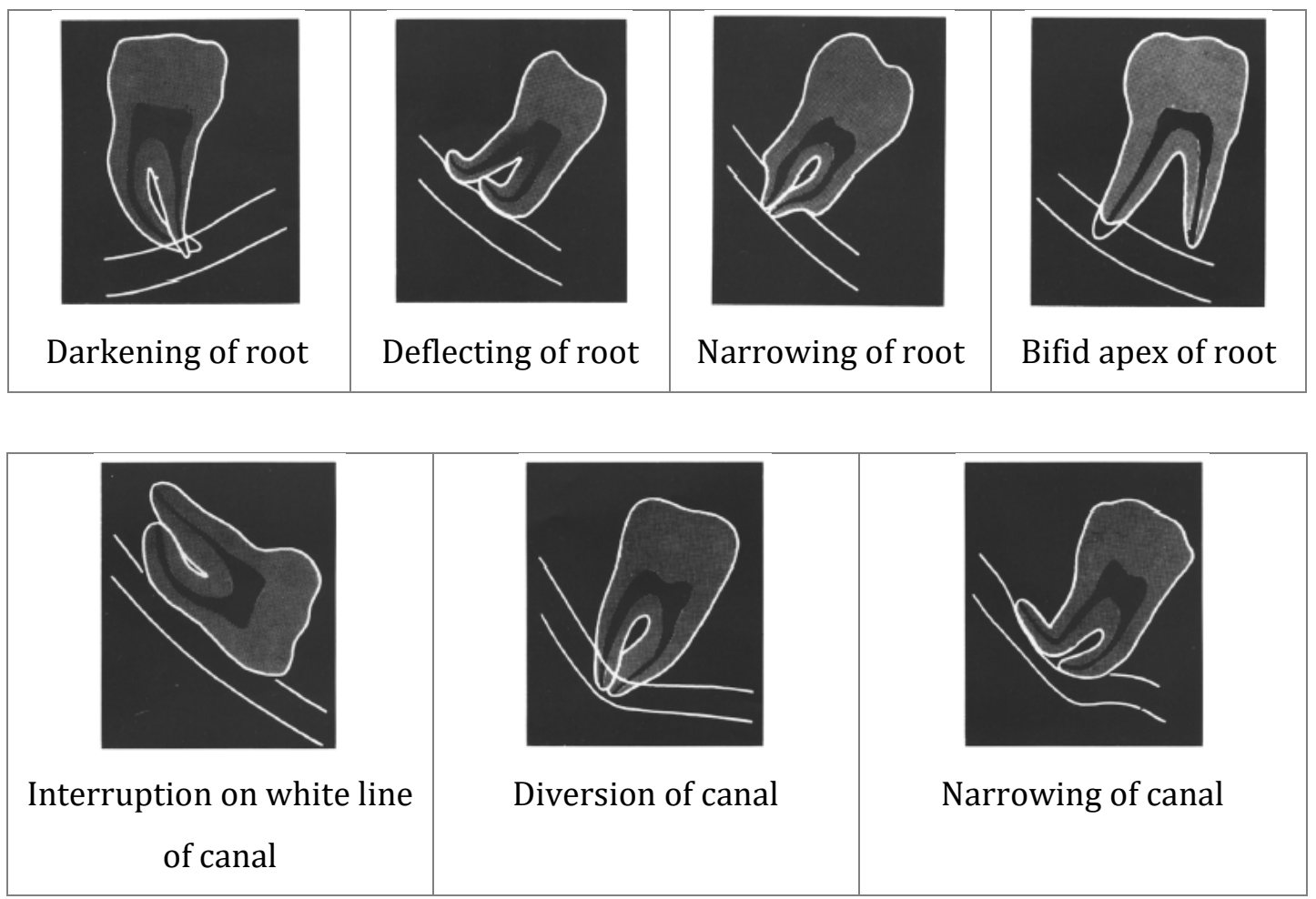

Figure 4. Seven signs of relationship of tooth to inferior dental canal

Therefore, accurate preoperative diagnosis and appropriate postoperative management can be achieved through a proper examination and investigation prior to the diagnosis (Susarla \& Dodson, 2004) and should be related to the operator's knowledge and skills.

1. To describe the number of MOS cases for impacted lower third molar received by IIUM undergraduates.

3. To compare the level of difficulty of MOS cases by using Pederson index according to the year of study, quadrant of tooth, Pell \& Gregory's classification, relationship to inferior dental nerve and tooth angulation.
5. To describe medications prescribed by IIUM undergraduates to the patients after MOS.

Hence, this research is important to assess case selection and suitability to the undergraduates and ultimately provide better treatment outcome to the patients.

\section{Materials and Methods}

\section{Study Design}

Retrospective study was implemented by utilizing records of all patients presented to IIUM Dental Clinic for MOS of impacted lower third molar by IIUM undergraduates from September 2014 to October 2015 via convenience sampling method.

\section{Patient Selection}

The study was a 1-year study which involved 97 samples. Several inclusion and exclusion criteria were made. The inclusion criterion for this study was: (1) MOS cases done by IIUM undergraduates within the timeline, whilst the exclusion criteria were: (1) MOS cases done by IIUM Specialists, (2) 
incomplete documentations and (3) cases other than impacted lower third molar.

\section{Research Tool and Data Collection}

\section{i. Patient's Record and Case Report}

Data of all patients underwent MOS for impacted lower third molar in IIUM Dental Clinic was screened for inclusion \& exclusion criteria. Patients' data were collected from PearlSuitev2 version 0.1.1.0, patient's case note, as well as student's case reports.

Demographic details and other epidemiological indicators - age, sex and race of the patients were collected from patient's record. Operator's year of undergraduate study was also recorded. The indications of MOS, presence of any postoperative complications and medications prescribed postoperatively were also extracted from the record.

\section{ii. Radiographic Examination}

Orthopantomogram (OPG) via Planmeca Romexis 2.8.0 was used to assess the condition and status of impacted lower third molar as well as the surrounding components such as bone, adjacent teeth, root formation, and relation to inferior dental nerve.

Figure 5 showed orthopantomogram and assessment was made as follows; Red line represented the occlusal level of impacted third molar with the adjacent tooth as well as its relationship to the ramus, Yellow lines represented the angulation of the third molar, and White lines showed the relation of third molar with inferior dental nerve.

To reduce inter-examiner error, calibration was done with Oral and Maxillofacial Surgery specialist prior to assessment of preoperative radiograph.

\section{Data and Statistical Analysis}

The data was analyzed using Statistical Package for Social Science (SPSS Graduate
Pack 16.0; SPSS Inc, Chicago, IL) version 16.0. Descriptive statistics were computed for each study variable. To measure the association between predictor and outcome variables, crosstab statistics were analyzed. Chi-square test was used to analyze the data. The level of statistical significance was set at $P \leq 0.05$.

\section{Ethical Consideration}

Ethical clearance was obtained from IIUM Research Ethics Committee (IREC). Approval date was on $8^{\text {th }}$ December 2015 with ID number IREC 508. All data regarding patient's identification and medical records were kept confidential.

\section{Result}

97 MOS cases performed by students from September 2014 to October 2015 were included in this study. From Table 2, most patients underwent MOS were in the age group between 15 and 24 years old, with a mean age of 24 years old. The male to female ratio was 1:1.9. 93.8\% patients were of Malay ethnicity.

Based on Figure 6, the most common indication for MOS was recurrent pericoronitis followed by unrestorable caries. $8.2 \%$ of cases have more than one indication. In other cases, the teeth were removed as prophylaxis to prevent subsequent complications from the impaction.

The occurrence of impacted lower third molar by quadrant was similar in number. Most cases were Class II ramus relationship (61.9\%), and Class A (80.4\%) in relation to the depth of impaction. No Class $\mathrm{C}$ case was done by students. Mesioangular and vertical impaction were the most common types of cases selected by students and the least common was distoangular impaction. Similar number of cases were recorded in term of proximity to the inferior alveolar nerve. 


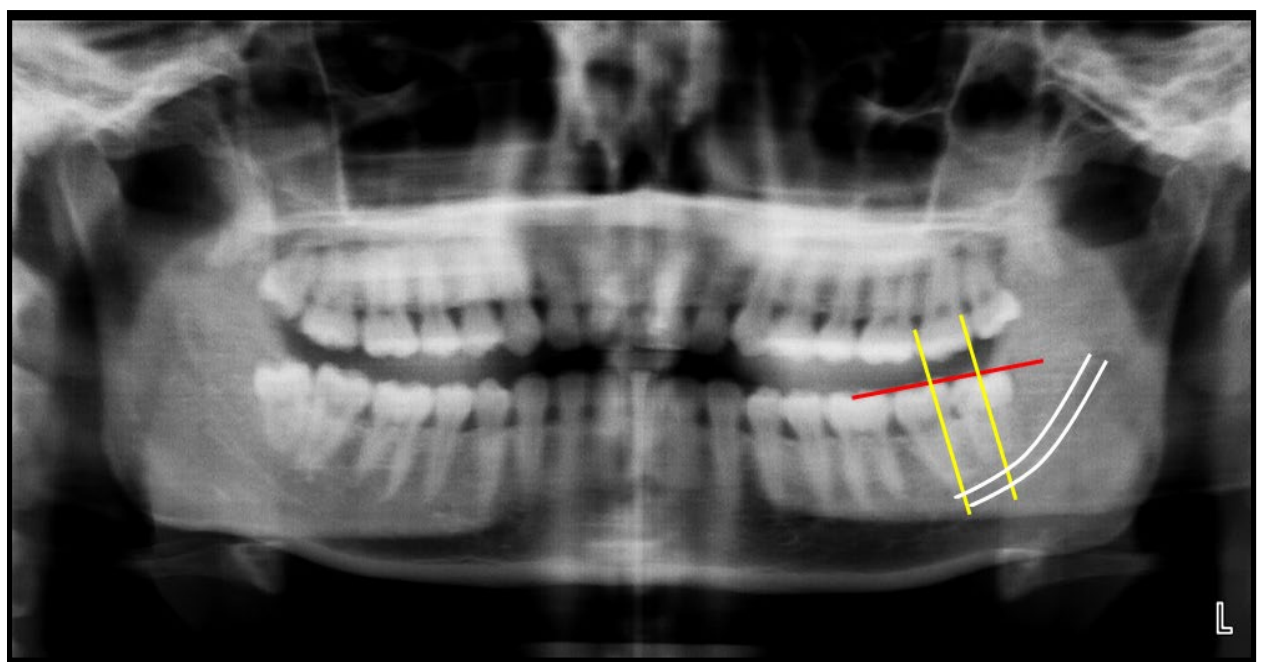

Figure 5. Orthopantomogram

Table 2. Patient's demographic data

\begin{tabular}{lc}
\multicolumn{1}{c}{ Patient's demographic data } & Frequency (\%) \\
Age & $61(62.9)$ \\
$15-24$ & $31(32.0)$ \\
$25-34$ & $5(5.2)$ \\
$35-44$ & $33(34.0)$ \\
Gender & $64(66.0)$ \\
Male & \\
Female & $91(93.8)$ \\
Race & $5(5.2)$ \\
Malay & $0(0.0)$ \\
Chinese & $1(1.0)$ \\
Indian &
\end{tabular}

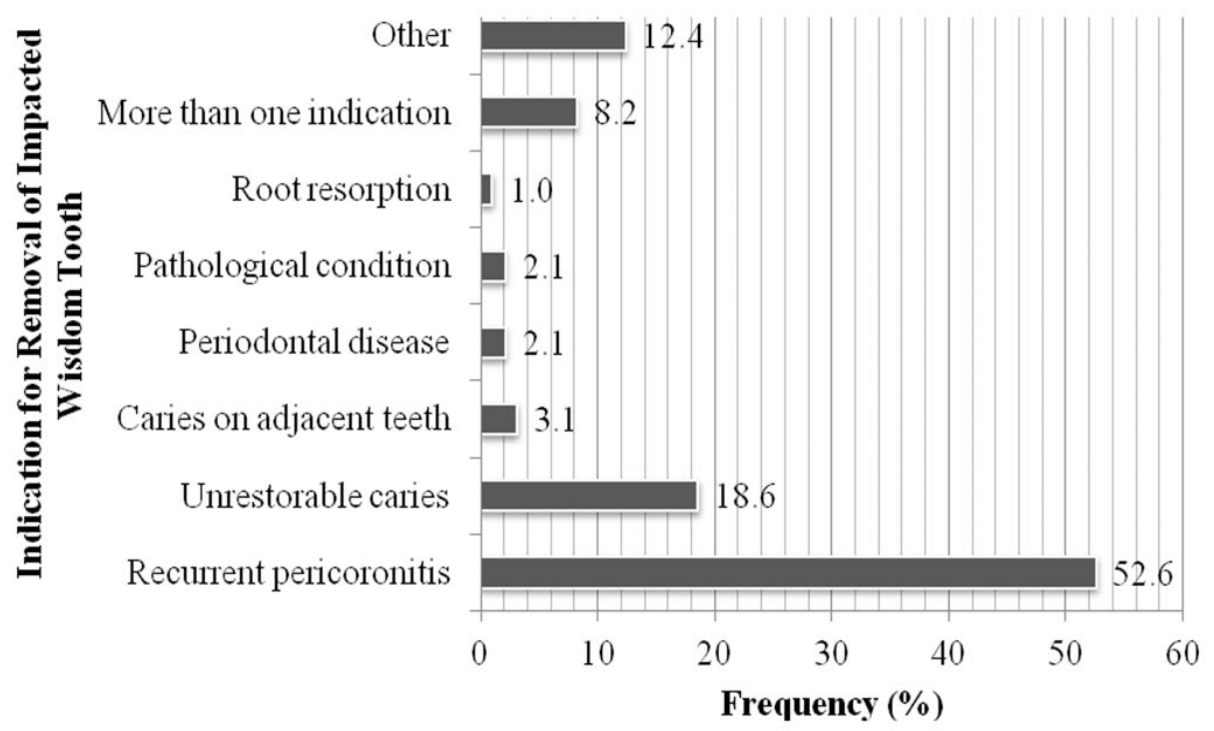

Figure 6. Distribution of indication for removal of impacted lower third molar 
The analysis for relation between associating factors and difficulty index level was done by Chi-square test (Table 3). Tooth quadrant, Pell and Gregory's classification and tooth angulation showed significant association with difficulty level $(P<0.05)$. Majority of left impacted third molar (tooth 38) cases were of moderate difficulty, whilst majority of right impacted third molar (tooth 48) cases were classified as easy.

Assessment of complications that arise after the surgery in relation to difficulty index level was shown in Table 4. High number of complications occurred although the cases were easy or moderate. There was no significant difference between level of difficulty and presence of complications.
Table 5 showed the relationship between year of undergraduate study and presence of complications. More complications occurred in Year 5 cases as compared to Year 4 cases. However, there was no significant relationship between year of undergraduate study and presence of complications ( $\mathrm{p}=0.493)$.

Table 6 showed that more than half of the cases were not prescribed with antibiotics. Regarding analgesic use, the most common type of analgesic prescribed was mefenamic acid $(43.3 \%)$, followed by combination between paracetamol and mefenamic acid (39.2\%).

Table 3. Relationship between associating factors and difficulty index level

\begin{tabular}{|c|c|c|c|c|}
\hline \multirow[b]{2}{*}{ Factors } & \multicolumn{3}{|c|}{ Difficulty Index } & \multirow[b]{2}{*}{$p$ value } \\
\hline & Easy & Moderate & Difficult & \\
\hline \multicolumn{5}{|l|}{ Undergraduate year } \\
\hline Year 4 student & 18 & 24 & 7 & \multirow{2}{*}{0.504} \\
\hline Year 5 student & 22 & 22 & 4 & \\
\hline \multicolumn{5}{|l|}{ Quadrant of tooth } \\
\hline Left, 38 & 15 & 30 & 4 & \multirow[t]{2}{*}{$0.023^{*}$} \\
\hline Right, 48 & 25 & 16 & 7 & \\
\hline \multicolumn{5}{|c|}{ Pell \& Gregory's classification } \\
\hline Class IA & 22 & 8 & 0 & \multirow[t]{9}{*}{$<0.001^{*}$} \\
\hline Class IB & 3 & 3 & 0 & \\
\hline Class IC & 0 & 0 & 0 & \\
\hline Class IIA & 15 & 28 & 4 & \\
\hline Class IIB & 0 & 6 & 7 & \\
\hline Class IIC & 0 & 0 & 0 & \\
\hline Class IIIA & 0 & 1 & 0 & \\
\hline Class IIIB & 0 & 0 & 0 & \\
\hline Class IIIC & 0 & 0 & 0 & \\
\hline \multicolumn{5}{|c|}{ Relation to inferior dental nerve } \\
\hline Close proximity & 21 & 25 & 3 & \multirow[t]{2}{*}{0.276} \\
\hline Away & 19 & 21 & 8 & \\
\hline \multicolumn{5}{|l|}{ Tooth angulation } \\
\hline Mesioangular & 36 & 2 & 0 & \multirow[t]{4}{*}{$<0.001^{*}$} \\
\hline Horizontal & 4 & 17 & 0 & \\
\hline Vertical & 0 & 26 & 7 & \\
\hline Distoangular & 0 & 1 & 4 & \\
\hline
\end{tabular}

*p-value $<0.05$ 
Table 4. Relationship between difficulty index level and presence of complications

\begin{tabular}{lllll} 
& \multicolumn{3}{c}{ Presence of complications } \\
& & Yes & No & Total \\
Difficulty index & Easy & 28 & 12 & 40 \\
& Moderate & 34 & 12 & 46 \\
Total & Difficult & 9 & 2 & 11 \\
& & 71 & 26 & 97
\end{tabular}

${ }^{*}$ p value $=0.768$

Table 5. Relationship between year of study and presence of complications

\begin{tabular}{lllll} 
& \multicolumn{3}{c}{ Presence of complications } \\
Undergraduate & Year 4 & 34 & No & Total \\
year & Year 5 & 37 & 15 & 49 \\
Total & & 71 & 11 & 48 \\
Potal & & 26 & 97
\end{tabular}

${ }^{*}$ p value $=0.493$

Table 6. Medications prescribed after MOS

$\begin{array}{ll}\text { Medications } & \text { Frequency (\%) } \\ \text { Antibiotic } & \\ \quad \text { Yes } & 35(36.1) \\ \text { No } & 62(63.9) \\ \text { Analgesic } & \\ \quad \text { None } & 1(1.0) \\ \text { Paracetamol } & 6(6.2) \\ \text { Mefenamic acid } & 42(43.3) \\ \text { Ibuprofen } & 3(3.1) \\ \text { Arcoxia } & 1(1.0) \\ \text { Paracetamol \& Mefenamic acid } & 38(39.2) \\ \text { Paracetamol \& Ibuprofen } & 1(1.0) \\ \text { Paracetamol \& Arcoxia } & 5(5.2)\end{array}$

\section{Discussion}

This research is the first study to evaluate MOS on impacted lower third molar performed by IIUM undergraduates. A total of 97 cases done by students from September 2014 to October 2015 were assessed in this study.

The mean age of patients underwent MOS in Kulliyyah of Dentistry, IIUM was 24 years old. There were more female patients $(66.0 \%)$ as compared to male. The high prevalence of female patients was similar to other studies (Al-Anqudi et al., 2014; Quek et al., 2003). This might be due to the smaller size of jaw in females as compared to males, making less space for the third molar to erupt (Shetty \& Banerjee, 2010).

Based on this study, the most common indication for the removal of the impacted lower third molar was recurrent pericoronitis (52.6\%). This is in accordance with the guideline by National Institute for Health \& Care Excellence (NICE) (2000). Another common indication was unrestorable caries (18.6\%). This result was in agreement with another study that reported the most common indication for MOS was recurrent pericoronitis (49.25\%), followed by caries $(26.1 \%$ ) (Abdulai et al., 2014). However, we also found that impacted lower third molar removal due to 
prophylactic reason was also high (12.4\%). This is contradicted with the NICE Guideline (2000) \& Clinical Practice Guideline by Ministry of Health (2005) that stated prophylaxis removal should not serve as an indication for MOS. This could be due to the lack of case selections from the waiting list available.

Radiological examination showed that most of the cases were mesioangulated (39.2\%). This was in concurrent with other studies that showed mesioangular impaction of lower third molar contributed about 33.4\% to $62 \%$ in prevalence (Al-Anqudi et al., 2014; Byahatti \& Ingafou, 2012; Hassan, 2010; Ma'aita, 2000; Obiechina et al., 2001; Othman, 2009; Quek et al., 2003). Based on Pell and Gregory's classification, the most common cases received by the students were Class IIA (48.5\%), followed by Class IA $(30.9 \%)$. There were no cases of Class C reported in the study as it has been specified by the department that students were not allowed to perform cases of Class $\mathrm{C}$, as well as cases with direct communication with the inferior alveolar nerve canal.

Most of the students operated on moderate cases $(47.4 \%)$, followed by easy cases $(41.2 \%)$ and difficult cases (11.3\%). The study showed that Year 4 students operated on more difficult cases as compared to Year 5 students. This is probably due to the limited number of patients for MOS in the waiting list, resulting in inability to allocate students according to the difficulty of cases. Additionally, students also brought their own patients for MOS, hence the mixture in case selection between Year 4 and Year 5 students.

The relationship between the difficulty level and presence of complications was not significant $(p=0.768)$. One of the probable reasons was most of the easy cases were done solely by the students with little help from the specialists. Thus, error in handling the surgery may occur and complications may result. In contrast, difficult cases were closely supervised by the skilled and experienced specialists resulting in minimal complications. Furthermore, higher number of complications noted in Year 5 students as compared to Year 4 students. This is probably because Year 4 students were beginners in handling the surgical procedure, hence they were closely supervised by the specialists. Meanwhile, Year 5 students received less supervision from the specialists. Thus, they tend to do more mistakes, and this led to complications. One of the most common complications was pain. This is probably occurred as a result of insufficient prescription of analgesic postoperatively (Susarla et al., 2003). From this study, it was found that the most common analgesic prescribed was mefenamic acid alone (43.3\%), followed by prescription of both paracetamol and mefenamic acid to the patient (39.2\%).

According to the World Health Organization (WHO) Pain Management Guidelines (2010), mild pain is prescribed with acetaminophen or paracetamol, or with non-steroidal antiinflammatory drugs (NSAIDs), with or without adjuvants. Recent study showed combination of acetaminophen and ibuprofen can be more effective to control pain after MOS compared to other types of analgesic (Merry et al., 2010). Pain may also be due to improper instructions given by the operator regarding the frequency of analgesic intake to the patient. According to WHO Pain Management Guidelines (2010), analgesic should be taken on regular basis at least one day postoperatively to control the pain effectively. Thus, there is a need to improve the knowledge on pain management and analgesic prescription post MOS.

Finally, our research showed that $36.1 \%$ of the patients were prescribed with antibiotic postoperatively. Recent studies revealed that average infection rates following MOS was less than $1 \%$ regardless of antibiotic administration (Bui et al., 2003; Haug et al., 2005; Mehrabi et al., 2007). According to Clinical Practice Guideline (CPG) for management of impacted lower third molar provided by Ministry of Health in Malaysia (2015), antibiotics prescription is considered only in cases of acute infection and in medically compromised patients. However, it was found that pattern of antibiotic prescription by the 
undergraduates did not comply to this guideline. Thus, there is a need to emphasize on appropriate antibiotics prescription to the students. Presently, the department is strictly following current guidelines by not prescribing antibiotic for non-indicated cases.

The main limitation in our study is the reduced number of cases presented due to incomplete or missing patient's documentation. Therefore, we recommend that this study should be further expanded by proper document keeping, followed by collecting bigger sample in order to obtain more comprehensive statistical analysis.

\section{Conclusion}

Overall, our undergraduates of year 4 and 5 received 97 patients for MOS with majority of them were due to recurrent pericoronitis. The complication was lesser in Year 4 in comparison to Year 5 although Year 4 received more difficult cases. There was no relationship between year of undergraduate study and the difficulty level of MOS. We also discovered that there was prescription of antibiotics without appropriate indications postoperatively.

\section{References}

Abdulai, A.E., Nuamah, I.K., Sackeyfio, J., \& Hewlett, S. (2014). Indications for surgical extraction of third molars: a hospital-base study in Accra, Ghana. International Journal of Medicine and Biomedical Research, 3(3), 155-160.

Al-Anqudi, S.M., Al-Sudairy, S., Al-Hosni, A., \& AlManiri, A. (2014). Prevalence and pattern of third molar impaction: A retrospective study of radiographs in Oman. Sultan Qaboos University Medical Journal, 14(3), 388-392.

Ali, K., McCarthy, A., Robbins, J., Heffernan, E., \& Coombes, L. (2014). Management of impacted wisdom teeth: teaching of undergraduate students in UK dental schools. European Journal of Dental Education, 18(3), 135-141.

Bali, A., Bali, D., Sharma, A., \& Verma, G. (2012). Is Pederson Index a true predictive difficulty index for impacted mandibular third molar surgery? A meta-analysis. Journal of Maxillofacial and Oral Surgery, 12(3), 359-364.

Bataineh A.B. (2001). Sensory nerve impairment following mandibular third molar surgery. Journal of Oral and Maxillofacial Surgery, 59(9), 10121017.
Batal, H.S., \& Jacobs, G. (2006). Surgical Extractions. In: Koerner K. R. (ed.), Manual of Minor Oral Surgery for The General Dentist (1st ed.). London: Blackwell Munksgaard, pp. 19-48.

Blaeser, B.F., August, M.A., Donoff, R.B., Kaban, L.B., \& Dodson, T.B. (2003). Panoramic radiographic risk factors for inferior alveolar nerve injury after third molar extraction. Journal of Oral and Maxillofacial Surgery, 61(4), 417-421.

Bui, C.H., Seldin, E.B., \& Dodson, T.B. (2003). Types, frequencies, and risk factors for complications after third molar extraction. Journal of Oral and Maxillofacial Surgery, 61(12), 1379-1389.

Byahatti, S., \& Ingafou, M.S. (2012). Prevalence of eruption status of third molars in Libyan students. Dental Research Journal, 9(2), 152-157.

Evans, A.W., Aghabeigi, B., Leeson, R.M., O'Sullivan, C., \& Eliahoo, J. (2002). Assessment of surgeon competency to remove mandibular third molar teeth. International Journal of Oral and Maxillofacial Surgery, 31(4), 434-438.

Fuselier, J.C., Ellis, E.E., 3rd, \& Dodson, T.B. (2002). Do mandibular third molars alter the risk of angle fracture? Journal of Oral and Maxillofacial Surgery, 60(5), 514-518.

Gülicher, D., \& Gerlach, K. (2001). Sensory impairment of the lingual and inferior alveolar nerves following removal of impacted mandibular third molars. International Journal of Oral and Maxillofacial Surgery, 30(4), 306-312.

Halmos, D.R., Ellis, E., 3rd, \& Dodson, T.B. (2004). Mandibular third molars and angle fractures. Journal of Oral and Maxillofacial Surgery, 62(9), 1076-1081.

Hassan A.H. (2010). Pattern of third molar impaction in a Saudi population. Clinical, Cosmetic and Investigational Dentistry, 2, 109-113.

Haug, R.H., Perrott, D.H., Gonzalez, M.L., \& Talwar, R.M. (2005). The American Association of Oral and Maxillofacial Surgeons age-related third molar study. Journal of Oral and Maxillofacial Surgery, 63(8), 1106-1114.

Hill, C., Mostafa, P., Thomas, D., Newcombe, R., \& Walker, R. (2001). Nerve morbidity following wisdom tooth removal under local and general anaesthesia. British Journal of Oral and Maxillofacial Surgery, 39(6), 419-422.

Hupp, J.R. (2014). Principles of Management of Impacted Teeth. In: Ellis, E. E. 3rd, Tucker, M. R. (eds.), Contemporary Oral and Maxillofacial Surgery (6 $6^{\text {th }}$ ed.). Missouri: Elsevier Mosby, pp. 143147.

Krimmel, M., \& Reinert, S. (2000). Mandibular fracture after third molar removal. Journal of Oral and Maxillofacial Surgery, 58(10), 1110-1112.

Ma'aita J.K. (2000). Impacted third molars and associated pathology in Jordanian patients. Saudi Dental Journal, 12, 16-19.

Malik, N.A. (2012). Minor Oral Surgical Procedures. In: Malik, N. A. (ed.), Textbook of Oral and Maxillofacial Surgery (3rd ed.). New Delhi: Jaypee Brothers Medical Publisher, pp. 147.

Mehrabi, M., Allen, J.M., \& Roser, S.M. (2007). Therapeutic agents in perioperative third molar surgical procedures. Oral and Maxillofacial Surgery Clinics of North America, 19(1), 69-84. 
Merry, A., Gibbs, R., Edwards, J., Ting, G., Frampton, C., Davies, E., et al., (2010). Combined acetaminophen and ibuprofen for pain relief after oral surgery in adults: a randomized controlled trial. British Journal of Anaesthesia, 104(1), 80-88.

Ministry of Health Malaysia (2005). Clinical Practice Guidelines: Management of Unerupted and Impacted Third Molar Teeth. Retrieved 8 January 2015, from https://www.moh.gov.my/moh/attachments/393 1.pdf

Ministry of Health Malaysia (2015). Clinical Practice Guidelines: Antibiotic Prophylaxis in Oral Surgery for Prevention of Surgical Site Infection. Retrieved 8 March 2021, from https://www.moh.gov.my/moh/resources/Pener bitan/CPG/Dental\%20\&\%200ral/CPG Antibiotic Prophylaxis in Oral Surgery Nov 2015.pdf

National Institute for Health \& Care Excellence (2000). Guidance on the Extraction of Wisdom Teeth. Retrieved 23 December 2015, from https://www.nice.org.uk/guidance/ta1/chapter/ 1-guidance

Obiechina, A.E., Arotiba, J.T., \& Fasola, A.O. (2001). Third molar impaction: evaluation of the symptoms and pattern of impaction of mandibular third molar teeth in Nigerians. Odontostomatologie Tropicale $=$ Tropical Dental Journal, 24(93), 22-25.

Othman R. (2009). Impacted mandibular third molars among patients attending Hospital Universiti Sains Malaysia. Archives of Orofacial Sciences, 4, 7-12.

Quek, S.L., Tay, C.K., Tay, K.H., Toh, S.L., \& Lim, K.C. (2003). Pattern of third molar impaction in a Singapore Chinese population: a retrospective radiographic survey. International Journal of Oral and Maxillofacial Surgery, 32(5), 548-552.

Shetty, P., \& Banerjee, S. (2010). Missing molars: A study on status of third molars. Journal of Pharmaceutical and Biomedical Sciences, 4(4), 1-3.

Susarla, S. M., Blaeser, B. F., \& Magalnick, D. (2003). Third molar surgery and associated complications. Oral and Maxillofacial Surgery Clinics of North America, 15(2), 177-18

Susarla, S. M., \& Dodson, T. B. (2004). Risk factors for third molar extraction difficulty. Journal of Oral and Maxillofacial Surgery, 62(11), 1363-1371.

World Health Organization (2010). WHO Pain Ladder with Pain Management Guidelines. Retrieved 31 December 2015, from https://www.southwesthealthline.ca/healthlibrar $\mathrm{y}$ docs/B.5.3.WHOPainLadder.pdf

Yuasa, H., Kawai, T., \& Sugiura, M. (2002). Classification of surgical difficulty in extracting impacted third molars. The British Journal of Oral \& Maxillofacial Surgery, 40(1), 26-31. 